\title{
The Expected Effect of Using eXtensible Business Reporting Language (XBRL) on the Extent of Using Ordinary Financial Statements by External Users in Jordan
}

\author{
Thaer Faisal Abdelrahim Qushtom \\ Accounting Sciences Department, \\ Faculty of Economics and Administrative Sciences, \\ Zarqa University, Zarqa, \\ P.O. Box 132222, Zarqa 13132, Jordan
}

DOI: https://doi.org/10.36941/ajis-2021-0137

\begin{abstract}
In 200o, a freely available modern global framework to exchange and communicate business information among business systems has emerged and called the eXtensible Business Reporting Language (XBRL). The $X B R L$ was designed to reduce differences in financial data presentation methods. The current study aimed mainly to find the feasibility of using the XBRL in Jordanian entities and the extent to which the ordinary financial statements can be replaced by the XBRL framework. A quantitative approach was used to collect and analyze data. Accordingly, 187 analyzable questionnaires were distributed and retrieved. The results showed that the majority of respondents are convinced that using the XBRL framework will provide them with relevant, reliable, comparable, timely, and required information. In addition, the coefficient measures showed that there is a significant negative relationship between using the XBRL framework and the use of ordinary financial reports at the significance level of 0.01 . Conversely, the results indicated that there is a significant positive relationship between using the XBRL framework and the usefulness of financial information in the planning and decision-making purposes. The results imply that Jordanian companies should turn to use the XBRL framework to present and communicate their financial reports, which will be reflected on increasing the confidence and interest of various users of financial reports in the company's results and management. Further, using the XBRL framework will enhance the planning and decisionmaking tools of users, which will be reflected on the interest of companies, especially those with good performance.
\end{abstract}

Keywords: eXtensible Business Reporting Language (XBRL), Financial Statements, External Users

\section{Introduction}

In the modern era, digital transformation has conquered all aspects of life, and the business was one of these aspects (Schallmo, Williams, \& Boardman, 2017). As all aspects of business, accounting has also affected by the digital transformation that has surrounded the entire accounting cycle (Troshani, Locke, \& Rowbottom, 2018). One of the most important stages of accounting cycle is the reporting, as many users (internal and external) rely extensively on financial statements in making their financial decisions (Cascino, et al., 2014). Over decades, the reporting of financial information has undergone many adjustments in terms of the required financial statements, the contents of financial statements, the forms of financial statements, and the methods of presenting and communicating financial 
statements(Unerman, Bebbington, \& O'dwyer, 2018). As a result, some differences have appeared in the mechanisms of preparing and presenting financial statements between entities due to the differences in business nature among these entities(Tiwari \& Shadab Khan, 2020). Accordingly, there were some difficulties in making comparative analysis between financial statements of various companies(Guay, Samuels, \& Taylor, 2016) (Chen, Collins, Kravet, \& Mergenthaler, 2018). However, in 2000, a new method of reporting, communicating and exchanging financial and business information has emerged and called the eXtensible Business Reporting Language (XBRL)(Hoitash, Hoitash, \& Morris, 2021). The XBRL is a freely available modern global framework to exchange and communicate business information among business systems, which depends on programming languages such as XML Schema, XLink, and XPath to define and exchange financial information (Ilias \& Ghani, 2015). Consequently, it has facilitated the presenting of semantic meaning that is commonly required in financial information in a systematic manner(Eierle, Ojala, \& Penttinen, 2014).

Since the advent of XBRL, there has been a marked increase in its usage in many developed countries such as the United States of America, United Kingdom, and Singapore (Eierle, Ojala, \& Penttinen, 2014). Despite that, the extent of using the XBRL in the developing countries still modest, which deprived entities and financial statements' users in these countries from many advantages associated with using this framework (Beerbaum \& Puaschunder, 2019). Same as all developing countries, the usage of XBRL in Jordan still non-existent (Abed, 2018). This fact indicates that entities, financial statements users, and decision-makers are ignorant of the benefits and importance of XBRL in helping them obtain correct, reliable, and comparable financial information that helps them in making rational economic decisions(Abed, 2018). Therefore, some studies were performed in the Jordanian business environment to encourage entities and decision-makers to switch to use the $\mathrm{XBRL}$, such as(Abed, 2018). However, these encouragement calls have not gained a response from financial statements' users and decision-makers. Thus, there is a need to highlight the benefits of using the XBRL framework and the extent to which using this framework affects the use of ordinary financial statements.

Knowing the expected effect of using the XBRL on the extent to which users use ordinary financial statements will help in determining the extent to which the global goals of the XBRL framework are achieved. In addition, it will assist in determining the feasibility of using the XBRL framework in various business environments, either in the developed or developing countries.

\subsection{Questions of Study}

In light of the calls of researchers in Jordan to switch to use the XBRL framework to benefit from its advantages, it is imperative to know the extent to which the use of this framework will affect the extent of using ordinary financial statements by users in Jordan that lacks of advanced technological infrastructure. In this vein, the following questions arise:

1. Does the use of XBRL in Jordan will affect the extent to which users use and rely on ordinary financial statements?

2. Does the use of XBRL in Jordan will provide users with the required financial data in an easy and effective way?

3. Does the use of XBRL in Jordan will enhance the usefulness of financial information for planning and economic decision-making purposes?

\subsection{Aims of Study}

The current study aims mainly to find the feasibility of using the XBRL in Jordanian entities and the extent to which the ordinary financial statements can be replaced by the XBRL framework. Finding that would shed light on the extent to which the XPRL framework satisfies the needs of users of financial statements with the information they need. In addition, it will give indications of the effectiveness of using this framework in the Jordanian business context. 


\subsection{Importance of Study}

As mentioned above, the XBRL framework was designed to reduce differences in financial data presentation methods by providing programmed standards to communicate and exchange commercial information, which facilitate the use of that information. Accordingly, the importance of the current study is reflected in determining the effectiveness of using the XBRL framework in satisfying users' needs in Jordan for financial information that enable them to make rational economic decisions. Further, the present study will help regulators and decision-makers in Jordan to identify the benefits that can be achieved through using the XBRL framework in presenting, communicating, and exchanging financial information.

\section{Literature Review}

Since the emergence of the XBRL in 2000, many studies have been carried out to explore its effectiveness from many aspects. In this vein, (Du \& $\mathrm{Wu}, 2018)$ found that the usage of XBRL reduces the required period to prepare and report financial statements. In addition, (Hsieh, Wang, \& Abdolmohammadi, 2019) concluded that the use of XBRL in the disclosure management solution affect positively the earnings release efficiency for companies that have good news. Further, (Liu, Luo, \& Wang, 2017) discovered that the adoption of XBRL among non-financial Europe firms increases significantly the market liquidity, which reflects on reducing information asymmetry among these firms. Moreover, (Amin, Eshleman , \& Feng, 2018) deduced that the mandatory use of XBRL led to decrease the lag in audit reports (on average) from 0.21 to 1.93 days in the period after use, and this decline is continued in the following years. Furthermore, (Torre, Valentinetti, Dumay, \& Rea, 2018) inferred that using XBRL in the integrated reporting enable stakeholders to shift from periodic and static reporting to more dynamic and relevant disclosure for stakeholders and enable them to retrieve and navigate the customized disclosure information. In this vein, (Chen, Kim, Lim, \& Zhou, 2018) found that the adoption of XBRL has positive effect on bank loans pricing through reducing the loan spreads especially for borrowers with inherently costlier processing information, as well as the XBRL enable lenders acquire and process relevant information at lower cost and timelier manner. Similarly, (Abdolmohammadi, DeSimone, Hsieh, \& Wang, 2017) concluded that the implementation of XBRL affects positively the quality of corporate governance in entities that have internal audit functions. Finally, (Pei \& Vasarhelyi, 2020) discovered that the use of XBRL by financial information users enable them recognizing, monitoring, and ensuring the resources in streamlined manner.

On the Jordanian context, (Abed, 2018) has conducted a study to explore the perspective of Jordanian professionalism toward the XBRL technology. She has found that there is low level of knowledge and awareness of XBRL usage. Further, she discovered that the Jordanian respondents would not accept and adopt the XBRL easily without understanding this framework and its programming language. In addition, (Slehat, 2018) has carried out a study to investigate the effect of technological, organizational, and environmental factors on adopting and implementing the XBRL framework in Jordanian companies. Slehat has found that Jordanian listed companies have the required infrastructure in terms of the technology, organization, and environment that enable them to adopt and implement the XBRL. Moreover, (Yassin, El-Barghouthi, \& Al-Khatib, 2012) have explored the expected benefits and obstacles of adopting the XBRL in Jordanian corporations and organizations from the perspective of academic members in Jordanian universities. Many benefits have been expected for adopting the XBRL in Jordanian entities, such as facilitating communication, analysis, and comparison of financial reports, as well as enhancing the quality, transparency, company's technological reputation, and the information value. On the other hand, the academic members have defined some expected obstacles of adopting the XBRL in Jordanian organizations, such as the lack of experts in XBRL framework, providing the required software and hardware, and finally the need for more time and effort. All previous studies have focused on many aspects related to the adoption and implementation of the XBRL framework in Jordan and other countries, but none 
of them addressed the extent to which the current ordinary financial reports could be substituted for the use of financial reports prepared through XBRL.

\section{Theoretical Framework}

The emergence of XBRL framework is a response to the global need to standardize the language of understanding financial reports and improving the ways they are prepared and communicated (Knebel \& Seele, 2015) (Mosteanu \& Faccia, 2020). Accordingly, many obstacles and negatives, which were major challenges in preparing, exchanging and analyzing financial reports, would be overcome (Faccia, Al Naqbi, \& Lootah, 2019). In addition, using the XBRL framework will provide users of financial reports with all information they need in ways that help them make their economic decisions more effectively (Eierle, Ojala, \& Penttinen, 2014). Therefore, it is assumed that users of financial statements will rely extensively on the XBRL framework, which should be reflected on reducing their use of ordinary financial statements.

According to the contingency theory of information technology developments, if the new technologies were fit the needs of business and enhance their operations in light of the appropriateness of their factors, then these technologies have to be implemented immediately (Ahimbisibwe, Cavana, \& Daellenbach, 2015). Based on that, the use of ordinary financial reports should be diminished with the existence of XBRL framework that is supposed to assist users of financial reports with greater levels of effectiveness.

\subsection{Hypotheses of Study}

Relying on the aforementioned discussion, the current study presents the following hypotheses:

H.1. There is negative relationship between using the XBRL framework and using the ordinary financial reporting.

H.2. The XBRL framework provides users with the required financial information in an easy and effective way.

H.3. There is positive relationship between using the XBRL framework and the usefulness of financial information for planning and economic decision-making purposes.

\subsection{Model of Study}

Based on the prior hypotheses, figure 1 shows the model of present study.

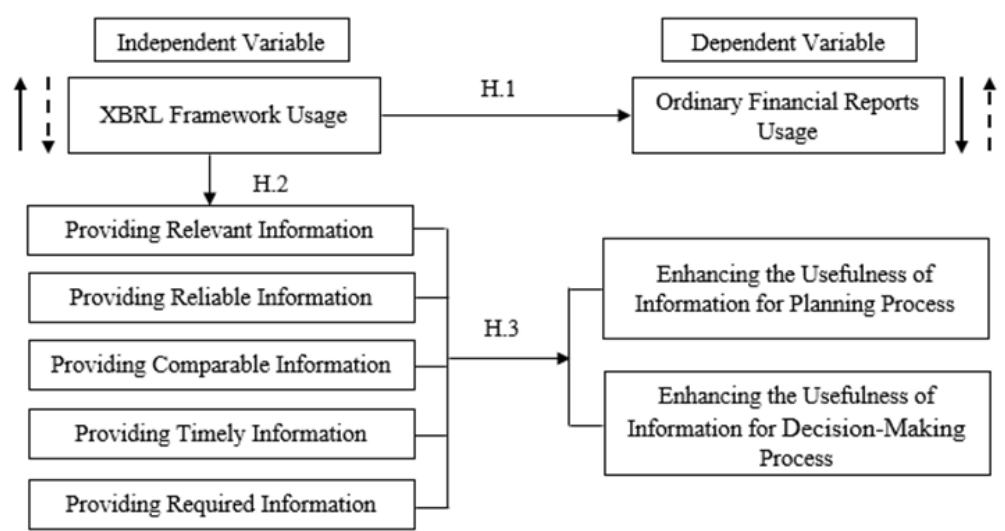

Figure 1: Model of Study 


\section{Methodology of Study}

In order to carry out the current study, a quantitative approach was used to collect and analyze data.

\subsection{Data Collection Method}

To collect data, a survey questionnaire was developed, which included four parts. The first part consisted of 6 questions that explored the demographic information of respondents. While the second part contained 16 questions focused on the features of XBRL framework and its suitability of users' needs (specifically the relevance, reliability, comparability, timely, and availability of information). The third part of questionnaire has involved 12 questions explored respondents' tendencies to use the financial reports issued by the XBRL framework instead of the ordinary financial reports. The last part of questionnaire consisted of 12 questions investigated the expected enhancement of XBRL information for users' decisions and plans.

\subsection{Population, Sample and Targeted Respondents}

All financial statements' users represent the population of the current study. In this vein, due to the presence of many users of financial statements and reports (such as shareholders, investors, lenders, and government agencies), the current research targeted three main categories, namely: shareholders in public joint-stock companies, financial managers in Jordanian companies, and bank managers. The purpose of targeting the previous three categories is the need to get data about the feasibility and tendency of using the XBRL framework from different points of view of different users. Accordingly, 245 questionnaires were distributed to a sample included 115 shareholders in public joint-stock companies, 95 financial managers in Jordanian companies, and 35 bank managers. The total number of retrieved analyzable questionnaires was 187 , with 95 questionnaires from shareholders in public joint stock companies, 68 questionnaires from a financial manager in Jordanian companies, and 24 questionnaires from bank managers.

\section{Data Analysis}

Before analyzing the collected data to test the research hypotheses, Cronbach Alpha was tested to ensure the reliability of questionnaire. The result of Cronbach Alpha was 0.72, which imply that the reliability of questionnaire is accepted (Taber, 2018).

The descriptive and multivariate regression analysis were used to test the research hypotheses. Descriptive analysis was used to explore the extent to which XBRL provides users with the required financial information in an easy and effective way, which is hypothesis number 2. In addition, multivariate regression analysis were used to test the relationships between the XBRL framework and the ordinary financial reporting, as well as between the XBRL framework and the usefulness of financial information, which are hypotheses number one and three.

\subsection{Descriptive and Normality Tests}

The descriptive statistics that are used to measure hypothesis are: the mean, minimum, median, maximum, in addition to Skewness ${ }^{1}$ and Kurtosis ${ }^{2}$ scales to measure the normality. Table 1 shows the descriptive and normality results.

\footnotetext{
${ }^{1}$ Skewness shows the symmetry or the lack of symmetry of the dataset.

${ }^{2}$ Kurtosis shows if data are heavy-tailed or light-tailed relative to a normal distribution.
} 
Table 1: Descriptive Statistics and Normality Tests of Variables

\begin{tabular}{lcccccc}
\hline Variable & Mean & Std. Dev. & Min & Max & Skewness & Kurtosis \\
Relevance of Information & 3.89 & 1.04 & 1 & 5 & 2.06 & 1.87 \\
Reliability of Information & 4.25 & 0.38 & 1 & 5 & 2.18 & 2.64 \\
Comparability of Information & 3.95 & 0.97 & 1 & 5 & -1.74 & -2.59 \\
Timely Information & 4.11 & 0.54 & 1 & 5 & -2.63 & 2.72 \\
\hline Required Information & 3.79 & 1.13 & 1 & 5 & -0.83 & 1.79 \\
\hline
\end{tabular}

Based on the descriptive results in table 1, the means of variables are ranged between 3.79 and 4.25, which imply that the majority of respondents are convinced that using the XBRL framework will provide them with relevant, reliable, comparable, timely, and required information. Despite that, the results of standard deviation indicate that there are extreme answers limits the ability of generalizing results, especially for the relevance of information and required information. In addition, the results of testing Skewness and Kurtosis in table 1 showed that the scales are ranged among -2.59 and 2.72, which indicate that the variables are normally distributed(Park, 2015). Moreover, to avoid any unforeseen problems in the heteroscedasticity when performing a regression test, the standardised residuals were calculated. Based on the standardised residuals values, the regressions are homoscedastic, which indicate that there are no problems in the heteroscedasticity.

\subsection{Multivariate Regression Tests}

Testing the relationships between using the XBRL framework and using the ordinary financial reporting, as well as using the XBRL framework and the usefulness of financial information for planning and economic decision-making purposes relied on the multivariate regression tests. Accordingly, two regression models were developed and performed. The first regression model tested the direct relationship between using the XBRL framework and using the ordinary financial reporting.

Ord_Rep_Use $=a 0+a 1 X B R L_{-} U s e+e i$

Where:

Ord_Rep_Use $=$ Ordinary Financial Reports Use, $a_{0}, a_{1}=$ The constants of the equation ; XBRL_Use $=$ XBRL Framework Use, ei $=$ The error term

While the second regression model tested the direct relationship between using the XBRL framework and the usefulness of financial information in the planning and decision-making purposes.

$$
\text { Fin_Info_Usef }=b 0+b 1 X B R L_{-} U s e+\varepsilon i
$$

Where:

Fin_Info_Usef $=$ Financial Information Usefulness, bo, b1 $=$ The constants of the equation ; XBRL_Use $=$ XBRL Framework Use, $\varepsilon \mathrm{i}=$ The error term

The results of performing the aforementioned two regression models are shown in table 2 .

Table 2. The relationship between using the XBRL framework and using the ordinary financial reporting, as well as between the XBRL framework and the usefulness of financial information. $(\mathrm{N}=$ 187)

\begin{tabular}{lcc} 
Variables & $\begin{array}{c}\text { Ord_Rep_Use } \\
\text { Coefficient Estimate }\end{array}$ & $\begin{array}{c}\text { Fin_Info_Usef } \\
\text { Coefficient Estimate }\end{array}$ \\
\hline Independent Variables & & 0.306 \\
\hline Constant & 0.074 & $(0.033)$ \\
& $(0.015)$ & $0.751^{*}$ \\
XBRL_Use & $-0.873^{* *}$ & $(0.019)$ \\
& $(0.008)$ & 0.389 \\
R Square & 0.355 & 0.366
\end{tabular}




\begin{tabular}{|c|c|c|}
\hline & Ord_Rep_Use & Fin_Info_Usef \\
\hline Variables & Coefficient Estimate & Coefficient Estimate \\
\hline \multicolumn{3}{|c|}{ Independent Variables } \\
\hline F-value & $289 \cdot 312$ & 312.532 \\
\hline Sig. Level & 0.004 & 0.016 \\
\hline \multicolumn{3}{|c|}{$\begin{array}{l}\text { P-value (Sig. Level) is reported in parentheses. } \\
{ }^{*} \text { Indicates p value is significant at level } 0.05,{ }^{* *} \text { Indicates p value is significant at level o.ol. }\end{array}$} \\
\hline \multicolumn{3}{|c|}{$\begin{array}{l}\text { Keys: (Ord_Rep_Use) Ordinary Financial Reports Use - (Fin_Info_Usef) Financial Information Usefulness. } \\
\text { (XBRL_Use) XBRL Framework Use. }\end{array}$} \\
\hline
\end{tabular}

\section{Results}

Based on the results in table 2, the use of XBRL framework has a significant negative relationship with the use of ordinary financial reports at the significance level of o.o1. This result indicates that the more use of XBRL framework the less use of ordinary financial reports. The adjusted $\mathrm{R}^{2}$ of the regressions between the use of XBRL framework and the use of ordinary financial reports is approximately $33 \%$. This finding indicates that the independent variable is able to explain nearly a third of changes in the use of ordinary financial reports. The regression has a good fit according to its F-value, which is significant at the o.o1 significance level. According to these results, the first hypothesis of the current study that hypothesis the presence of significant negative relationship between the use of XBRL framework and the use of ordinary financial reports is accepted.

In addition, the results in table 2 showed that the use of XBRL framework has a significant positive relationship with the usefulness of financial information in the planning and decisionmaking purposes at the significance level of 0.05. This result indicates that the more use of XBRL framework the more usefulness of financial information in the planning and decision-making purposes. The adjusted $\mathrm{R}^{2}$ of the regressions between the use of XBRL framework and the usefulness of financial information in the planning and decision-making purposes is approximately $36 \%$. This finding indicates that the independent variable is able to explain more than a third of changes in the usefulness of financial information in the planning and decision-making purposes. The regression has a good fit according to its F-value, which is significant at the 0.05 significance level. Based on these results, the second hypothesis of the current study that hypothesis the presence of significant positive relationship between the use of XBRL framework and the usefulness of financial information in the planning and decision-making purposes is accepted.

\subsection{Discussion and Conclusion}

From the outset, the current research has mainly sought to determine whether using the XBRL framework will reduce the use of ordinary financial reports by users in Jordan. According to the prior results, the use of XBRL will reduce the use of ordinary financial reports. The researcher believes that this result is due to the fact that the XBRL framework facilitates the process of analyzing and comparing financial data (Gomaa, Markelevich, \& Shaw, 2011), as well as it provides the financial data in a timely manner (Seele, 2016). Additionally, this result may be due to the fact that the world is rapidly moving into digital transformation (Lombardi \& Secundo, 2020), which requires everyone to keep pace with this transformation. In this vein, (Enachi \& Andone, 2015) have pointed out that the trend to use the XBRL framework is increasing with the passage of time, and therefore most companies will adopt this framework later to provide financial data for users. In addition, (Pan \& Seow, 2016) have explained that technological development and the transition to digital systems in the world will force everyone to move from ordinary methods to technological methods of exchanging and processing information. Further, (Kaya \& Pronobis, 2016) have indicated that the advantages of using the XBRL framework will push enterprises and users of financial information to adopt this framework sooner or later. Finally, (Rostami \& Nayeri, 2015) clarified that the development of technological skills among users of financial statements will make them inclined to use the XPRL 
framework.

Moreover, the present study has aimed to find out if the XBRL characteristics will meet the needs of users and help them more than the ordinary financial reports. The descriptive results showed that the financial users prefer to use the XBRL framework, as it will provide them with more relevant, analyzable, comparable, and timely information. The researcher expects that the reason for this result is the knowledge of users of financial statements of the importance of time in making financial decisions (Seele, 2016), as well as the importance of comparability and analyzability for making optimal decisions (Geiger, North, \& Selby, 2014). Further, this result may be due to the fact that people know that using information technology is more effective than using traditional systems (Pan \& Seow, 2016). In this regard, (Hsieh, Wang, \& Abdolmohammadi, 2019) indicated that the features of the XBRL framework would be attractive factors for users to use and adopt this framework. In addition, (Baldwin \& Trinkle, 2011) have explained that users of the XBRL framework will be more efficient in their business performance than users of regular systems due to the features of the XBRL framework.

Finally, the current study has pursued to explore if the use of XBRL framework increases the usefulness of financial information for planning and decision-making purposes. Based on the results, the use of XBRL framework increase the usefulness of financial information for the aforementioned purposes. The researcher expects that the relevancy, reliability, comparability, timely of information are the major factors for increasing the usefulness of financial information extracted from the XBRL framework. In this context, (Alles \& Piechocki, 2012) have explained that obtaining the necessary information in a timely manner is one of the main factors in the success of entities to take appropriate decisions. Further, (Arnold, Bedard, Phillips, \& Sutton, 2012) have explained that optimal investment decisions depend on comparing financial information for all available alternatives. Furthermore, (Hodge, Kennedy, \& Maines, 2004) have mentioned that obtaining reliable information increases the validity of the decisions taken.

\subsection{Implications of Study}

The results of the current study indicate to some significant implications. The first implication is the importance of Jordanian companies to turn to use the XBRL framework to present and communicate their financial reports. The turning to use the XBRL framework will be reflected on increasing the confidence and interest of various users of financial reports in the company's results and management.

The second implication is the desire and tendency of various financial statements users to switch to use the financial reports that will be issued by the XBRL framework. Using the financial reports that will be issued by the XBRL framework by various users will help them and facilitate their study of these reports. Therefore, using the XBRL framework will not lead to negative consequences of companies by users.

Finally, using the XBRL framework will enhance the planning and decision-making tools of users, which will be reflected on the interest of companies, especially those with good performance, as this will attract investors and those interested in dealing with those companies.

\subsection{Recommendations of Study}

In light of the current study results, the researchers recommend Jordanian companies to switch to use the XBRL framework to present and communicate their financial reports. In addition, the researchers recommend users to benefit from the features of the XBRL framework, especially the relevancy, comparability, and timely of information. Further, the researchers recommend users to work on enhancing their skills in using technology to be able to exploit all the features and advantages of the XBRL framework. Finally, the researchers recommend that the legislators in Jordan study the drafting of a law that imposes the use of the XBRL framework on public shareholding 
companies, which may have positive effects on increasing the activity of transactions in financial markets.

\subsection{Limitation of Study and Suggestions for Future Studies}

The reader of the current study should note that there were some limitations surrounded it. These limitations are, the sample of the current study focused on three categories of financial statements users, namely: shareholders in public joint-stock companies, financial managers in Jordanian companies, and bank managers. Accordingly, there are other categories of financial statements' users were not included in the sample of the current study. Based on that, the researchers suggest conducting similar studies focus on other categories of users to explore their tendencies of using the XBRL framework.

In addition, the methodology of collecting and analyzing data relied on quantitative methods, which may be affected by the bias of respondents' answers. Consequently, other researchers are advised to carry out similar researches using other methods, such as qualitative and mixed methods, to ensure the results' validity of the current study.

Finally, it should be noted that the current study is limited on the Jordanian business settings. Therefore, the results of the current study should not be generalized to other countries. Accordingly, the researchers recommend conducting similar studies in other countries to explore the feasibility of using the XBRL framework in various countries over world and its impact on the use of ordinary financial statements by their users.

\section{Acknowledgements}

The researchers would like to acknowledge Zarqa University - Jordan represented by its administration for their contribution to the success of this study through the full support and providing the required facilities to collect and analyze data. In addition, they would like to acknowledge all respondents who filled out the questionnaire of the present study.

\section{References}

Abdolmohammadi, M. J., DeSimone, S. M., Hsieh, T.-S., \& Wang, Z. (2017). Factors associated with internal audit function involvement with XBRL implementation in public companies: An international study. International Journal of Accounting Information Systems, 25, 45-56. doi:https://doi.org/10.1016/j.accinf.2017.03.002

Abed, S. R. (2018). The perception of XBRL technology in the Jordanian context: An exploratory study. Research Journal of Applied Sciences, 13(1), 1-4.

Ahimbisibwe, A., Cavana, R. Y., \& Daellenbach, U. (2015). A contingency fit model of critical success factors for software development projects: A comparison of agile and traditional plan-based methodologies. Journal of Enterprise Information Management, 28(1), 7-33. doi:https://doi.org/10.1108/JEIM-08-2013-0o6o

Alles, M., \& Piechocki, M. (2012). Will XBRL improve corporate governance?: A framework for enhancing governance decision making using interactive data. International Journal of Accounting Information Systems, 13(2), 91-108. doi:https://doi.org/10.1016/j.accinf.2010.09.008

Amin, K., Eshleman , J. D., \& Feng, C. (. (2018). The Effect of the SEC's XBRL Mandate on Audit Report Lags. Accounting Horizons, 32(1), 1-27. doi:https://doi.org/10.2308/acch-51823

Arnold, V., Bedard, J. C., Phillips, J. R., \& Sutton, S. G. (2012). The impact of tagging qualitative financial information on investor decision making: Implications for XBRL. International Journal of Accounting Information Systems, 13(1), 2-20. doi:https://doi.org/10.1016/j.accinf.2011.12.002

Baldwin, A. A., \& Trinkle, B. S. (2011). The Impact of XBRL: A Delphi Investigation. The International Journal of Digital Accounting Research, 11, 1-24. doi:10.4192/1577-8517-v11_1

Beerbaum, D., \& Puaschunder, J. M. (2019). Towards an XBRL-enabled Sustainability Taxonomy - A behavioral accounting approach. Journal of Applied Research in the Digital Economy, 2(1). 
Cascino, S., Clatworthy, M., Osma, B. G., Gassen, J., Imam, S., \& Jeanjean, T. (2014). Who Uses Financial Reports and for What Purpose? Evidence from Capital Providers. Accounting in Europe, 11(2), $185-209$. doi:10.1080/17449480.2014.940355

Chen, C.-W., Collins, D. W., Kravet, T. D., \& Mergenthaler, R. D. (2018). Financial Statement Comparability and the Efficiency of Acquisition Decisions. Contemporary Accounting Research, 35(1), 164-202.

Chen, G., Kim, J.-B., Lim, J.-H., \& Zhou, J. (2018). XBRL Adoption and Bank Loan Contracting: Early Evidence. Journal of Information Systems, 32(2), 47-69. doi:https://doi.org/10.2308/isys-51688

Du, H., \& Wu, K. (2018). XBRL Mandate and Timeliness of Financial Reporting: Do XBRL Filings Take Longer? Journal of Emerging Technologies in Accounting, 15(1), 57-75. doi:https://doi.org/10.2308/jeta-52094

Eierle, B., Ojala, H., \& Penttinen, E. (2014). XBRL to enhance external financial reporting: Should we implement or not? Case Company X. Journal of Accounting Education, 32(2), $160-170$. doi:https://doi.org/10.1016/j.jaccedu.2014.04.003

Enachi, M., \& Andone, I. I. (2015). The Progress of XBRL in Europe - Projects, Users and Prospects. Procedia Economics and Finance, 20, 185-192. doi:https://doi.org/10.1016/S2212-5671(15)ooo64-7

Faccia, A., Al Naqbi, M. Y., \& Lootah, S. A. (2019). Integrated Cloud Financial Accounting Cycle: How Artificial Intelligence, Blockchain, and XBRL will Change the Accounting, Fiscal and Auditing Practices. Proceedings of the 2019 3rd International Conference on Cloud and Big Data Computing, (pp. 31-37). doi:https://doi.org/10.1145/3358505.3358507

Geiger, M. A., North, D. S., \& Selby, D. D. (2014). Releasing Information in XBRL: Does It Improve Information Asymmetry for Early U.S. Adopters? Academy of Accounting and Financial Studies Journal, 18(4), 66-83.

Gomaa, M. I., Markelevich, A., \& Shaw, L. (2011). Introducing XBRL through a financial statement analysis project. Journal of Accounting Education, 29(2-3), 153-173.

Guay, W., Samuels, D., \& Taylor, D. (2016). Guiding through the Fog: Financial statement complexity and voluntary disclosure. Journal of Accounting and Economics, 62(2-3), 234-269.

Hodge, F. D., Kennedy, J. J., \& Maines, L. A. (2004). Does Search-Facilitating Technology Improve the Transparency of Financial Reporting? The Accounting Review, 79(3), 687-703. doi:https://doi.org/10.2308/accr.2004.79.3.687

Hoitash, R., Hoitash, U., \& Morris, L. (2021). eXtensible Business Reporting Language: A Review and Implications for Future Research. AUDITING: A Journal of Practice E Theory. doi:https://doi.org/10.2308/AJPT-2019-517

Hsieh, T.-S., Wang, Z., \& Abdolmohammadi, M. (2019). Does XBRL disclosure management solution influence earnings release efficiency and earnings management? International Journal of Accounting $\mathcal{E}$ Information Management, 27(1), 74-95. doi:https://doi.org/10.1108/IJAIM-o6-2017-0079

Ilias, A., \& Ghani, E. K. (2015). Examining the Adoption of Extensible Business Reporting Language among Public Listed Companies in Malaysia. Procedia Economics and Finance, 28, 32-38. doi:https://doi.org/10.1016/S22125671(15)01078-3

Kaya, D., \& Pronobis, P. (2016). The benefits of structured data across the information supply chain: Initial evidence on XBRL adoption and loan contracting of private firms. Journal of Accounting and Public Policy, 35(4), 417-436. doi:https://doi.org/10.1016/j.jaccpubpol.2016.04.003

Knebel, S., \& Seele, P. (2015). Quo vadis GRI? A (critical) assessment of GRI 3.1 A+ non-financial reports and implications for credibility and standardization. Corporate Communications: An International Journal, 2o(2), 196-212. doi:https://doi.org/10.1108/CCIJ-11-2013-0101

Liu, C., Luo, X. (., \& Wang, F. L. (2017). An empirical investigation on the impact of XBRL adoption on information asymmetry: Evidence from Europe. Decision Support Systems, 93, 42-50. doi:https://doi.org/10.1016/j.dss.2016.09.004

Lombardi, R., \& Secundo, G. (2020). The digital transformation of corporate reporting - a systematic literature review and avenues for future research. Meditari Accountancy Research. doi:https://doi.org/10.1108/MEDAR04-2020-0870

Mosteanu, N. R., \& Faccia, A. (2020). Digital Systems and New Challenges of Financial Management - - FinTech, XBRL, Blockchain and Cryptocurrencies. Journal of Management Systems - Quality Access to success, 21(174), 159-166.

Pan, G., \& Seow, P.-S. (2016). Preparing accounting graduates for digital revolution: A critical review of information technology competencies and skills development. Journal of Education for Business, 91(3), 166175. doi:https://doi.org/10.108o/o8832323.2016.1145622

Park, H. M. (2015). Univariate analysis and normality test using SAS, Stata, and SPSS*. IUScholarworks. Indiana, US: Indiana University. 
Pei, D., \& Vasarhelyi, M. A. (2020). Big data and algorithmic trading against periodic and tangible asset reporting: The need for U-XBRL. International Journal of Accounting Information Systems, 37. doi:https://doi.org/10.1016/j.accinf.2020.100453

Rostami, M., \& Nayeri, M. D. (2015). Investigation on XBRL Adoption Based on TOE Model. Journal of Economics, Management and Trade, 7(4), 269-278. doi:https://doi.org/10.9734/BJEMT/2015/16879

Schallmo, D., Williams, C. A., \& Boardman, L. (2017). Digital Transformation of Business Models — Best Practice, Enablers, and Roadmap. International Journal of Innovation Management, 21(8), 1-17. doi:https://doi.org/10.1142/S136391961740014X

Seele, P. (2016). Digitally unified reporting: how XBRL-based real-time transparency helps in combining integrated sustainability reporting and performance control. Journal of Cleaner Production, 136(Part A), 65-77.

Slehat, Y. (2018). Affecting Factors on eXtensible Business Reporting Language (XBRL) Adoption Among Public Listed Companies in Amman Stock Exchange. Australian Journal of Basic and Applied Sciences, 12(6), 36-40.

Taber, K. S. (2018). The Use of Cronbach's Alpha When Developing and Reporting Research Instruments in Science Education. Research in Science Education, 48, 1273-1296. doi:https://doi.org/10.1007/s11165-016-96022

Tiwari, K., \& Shadab Khan, M. (2020). Sustainability accounting and reporting in the industry 4.o. Journal of Cleaner Production, 258(10 June)

Torre, M. L., Valentinetti, D., Dumay, J., \& Rea, M. A. (2018). Improving corporate disclosure through XBRL: An evidence-based taxonomy structure for integrated reporting. Journal of Intellectual Capital, 19(2), 338-366. doi:https://doi.org/10.1108/JIC-03-2016-0030

Troshani, I., Locke, J., \& Rowbottom, N. (2018). Transformation of accounting through digital standardisation: Tracing the construction of the IFRS Taxonomy. Accounting, Auditing E Accountability Journal, 32(1), 133162.

Unerman, J., Bebbington, J., \& O'dwyer, B. (2018). Corporate reporting and accounting for externalities. Accounting and Business Research, 48(5), 497-522.

Yassin, M., El-Barghouthi, S., \& Al-Khatib, I. (2012). XBRL: The Future of Financial Reporting in Jordan. International Conference on Business Intelligence and Knowledge Economy (pp. 23-26). Amman: Al Zaytoonah University of Jordan, Faculty of Economics and Administrative Sciences. 